\title{
Fire Detection and Human Behaviour
}

\author{
B. B. PIGOTT \\ Fire Research Station \\ Borehamwood Herts \\ WD6 2BL, UK
}

ABSTRACT

The paper draws together the two separately researched topics

- human behaviour in fire and human response to informative fire warning systems

- computer-based automatic fire detection systems ('intelligent fire alarms')

The paper summarises some salient points reached so far and combines them with observations on first aid fire fighting by the population of the UK, in order to outiline a fire protection strategy.

Work on human response to fire warning systems is a continuing project. However indications are that the low cost methods being investigated to give information to occupants of a building early in a fire will be sufficiently precise to reduce the need for highly expensive fire protection measures.

KEYWORDS: Human Behaviour, Detection, Computer, Escape, Fire Protection.

\section{INTRODUCTION}

For more than a decade now, the Fire Research Station (FRS) has sponsored researoh into human behaviour. This work has been undertaken mainly by the University of Surrey Fire Research Unit. The team initially investigated human behaviour in fires of varying severity in many occupational groups (1). When it had developed a good understanding of behaviour in fire emergencies, the Unit was asked to explore the possibilities for modifying behaviour to increase life safety, using the technology offered by newly developed computer-based fire alarm systems (2).

In 1970 FRS published an investigation into false fire alarms from automatic detection systems (3) which indicated a ratio of 11 false alarms to each genuine fire. Subsequent surveys undertaken by the British Fire Protection Systems Association showed the less favourable ratio of $16: 1$. Over the years the number of installed systems has increased and the burden on the fire brigades became a matter for concern. Supported by suggestions in a Home office review (4), the FRS 
embarked on the investigation of computer-based automatic fire detection systems (AFDS) with the intention of using a microcomputer's

decision-making ability to mitigate the known causes of false alarms.

This programme has been successful in its primary task of false alarm control. Similar developments had taken place in Norway, then Germany and later in Japan. However, in the UK, FRS has been in a position to see the advantages of drawing on research into human behaviour to make use of the fire intelligence avallable within advanced detection systems. The rapid advance of personal microcomputers has enabled it to extend the scope of research on the effectiveness of fire inteliigence to equipment offering text to speech and very fast colour graphics capabilities at low cost.

Some detailed findings of the two research programmes will be outlined and their potential for promoting low cost personal safety discussed.

\section{RESEARCH INTO HUMAN BEHAVIOUR IN FIRE}

The Fire Research Unit at Surrey University promised hypotheses of behaviour supported by case histories from the research team's interviews, and its analyses of public enquiries, police statements and press reports. It was quite outside the scope of avallable budgets and stafe to attempt a statistical 'proof'. In the event, a model of human behaviour in fire situations has been prepared (5) which is convincing and is summarised in Figure 1.

Stages

1) Interpret

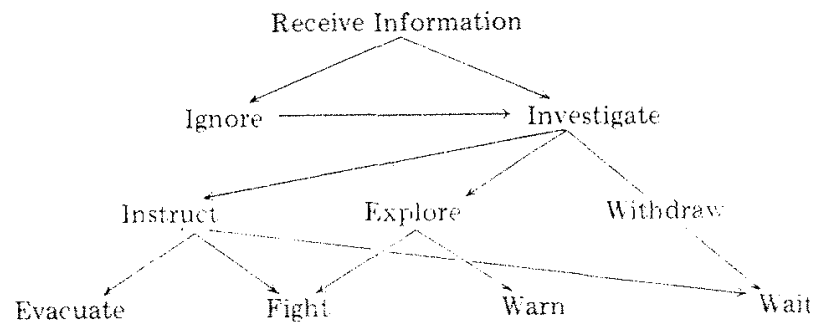

3) Act

Evacuate

Eigure 1. General model of human behaviour in fires

Several principal findings came out of the work, some of which have been taken up by other research groups and have even entered the 'folk lore' of fire protection thinkins. They are not however wholly coincident with the aims of traditional fire protection measures. Moreover, there still remains the problem of what to do about these findings. Meanwhile, let us outline them:

1) Building occupants were found not to use escape routes which were unfamiliar to them. This implies that purpose built fire escapes might be less than wholly effective, particularly to those unfamiliar with the bullding.

2) Building occupants tended to behave in a manner strongly dictacted by the 'role' in which they saw themselves: 
- hotels: staff behave differently from guests;

- hospital: staff continue duties to patients;

- dwellings: parents secure safety of children.

3) Early clues to the presence of fire were generally ambiguous, such as strange noises like breaking glass and extra activity by others, rather than direct evidence of fire or smoke. Almost always, escape from fire was preceded by a phase of seeking additional information. The Unit refers to this as the 'gathering' phase, and this phenomenon appears in studies of each occupational group. It points out that such delay can be particularly dangerous, as actions taken at the early stages of the fire have the most decisive effect on the eventual outcome.

4) The response to fire alarm bells and sounders tended to be poor. There was usually a high degree of scepticism as to whether the noise indicated a fire alarm and if so, was the alarm merely a system test or dri11?

5) Perhaps the most important finding, arrived at by interviews with people severely threatened by fire, was that the much used concept of 'panic' was a blanket term used to describe behaviour resulting from the very limited information available to individuals. The team pointed out (6) that fire analyses were generally conducted by people having full knowledge of the fire development, the building and its escape routes. However, those fire victims exhibiting behaviour that might at first seem irrational could have, at best, a very imperfect knowledge of those facts. They might also be worried about the safety of those for whom they felt a responsibility.

\section{THE DEVELOPMENT OF 'INTELLIGENT FIRE ALARM SYSTEMS'}

Based on some early research on ambient conditions in non-fire environments, coupled with detailed knowledge of the findings of various false alarm surveys, FRS published a paper in 1974 (7), suggesting that false alarms arose from three main causes, in almost equal proportions. These were caused by the environment (heat, moisture, dust, wind etc), the equipment (electrical, mechanical etc) and human interference (testing without first informing the fire brigade etc). The paper postulated rates of false alarms and fire detection to be expected of a single detector (once in ten years and once in 250 years respectively) It also suggested that a sensor's response to ambient conditions could be represented by a simple exponential function - so permitting an estimate of false alarm performance (Figure 2).

All of these observations have stood up to later investigation. However, the dramatic reduction of price of computing equipment has permitted the prototyping, and lately the widespread manufacture of computer-based automatic fire detection (AFD) systems. This type of equipment (8) is capable of undertaking the continuous monitoring of individual fire sensors at an economic cost. In such systems, simple electronic design should ensure that no switch, sounder, sensor, or its associated wiring, will give rise to an alarm when open or short circuited. 


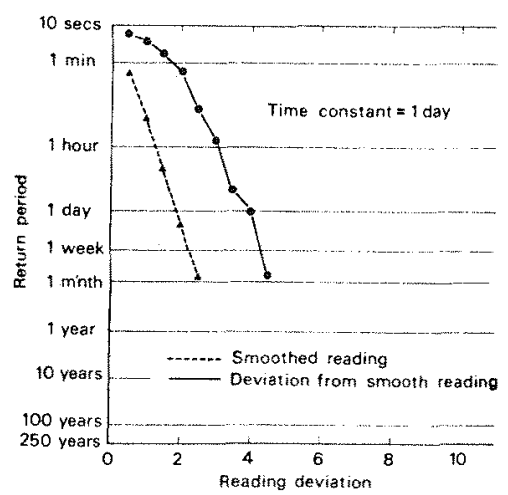

Figure 2. Typical sensor deviation from mean plotted against log time

Given a reasonably accurate representation of the output of each fire 'sensor' (measuring device), it is possible to compensate the reading for drift with time. The amount of compensation necessary to correct the drift can itself be used as a measure of probable serviceability, permitting 'demand' maintenance. Thus with such systems, the owner will become aware as to whether maintenance needs to be carried out or not.

The output of sensors in the prototype equipment installed at the FRS do indeed demonstrate the predictions of so long ago. It is therefore theoretically possible to tailor sensor output for an approximate sensitivity to false alarm ratio. Such environmental characterisation can reasonably be calculated after about a week of operation. It was noted that the effect of lighting a cigar, in a medium sized office, was about $1 / 8$ of that needed to trigger an alarm.

All these new generation 'intelligent' AFD systems are capable of identifying any trigger device. The better ones can do this in terms of floor, room, position number and device type. Given this information at a central point - say the control equipment - it is possible for such a system to provide a continuous picture, not only of the origin of a fire but also of its spread and even of smoke density.

For effective use in life safety, considerable attention must be paid to the design and maintenance of the computing system (9). FRS prototypes, in common with the better commercial systems, ensure that message integrity is protected within the system using checking techniques common in the computer industry. The computer must restart automatically if affected by electrical/magnetic disturbances not filtered out by the normal precautions. Furthermore, the earliest and subsequent FRS prototypes were designed for surveillance by an offsite computer which could report on serviceability and receive specific information on the location of fires and faults and such further site details as the fire brigade might need to mount a rapid and safe attack on the fire.

\section{CORRELATION OF THE TWO TOPICS}

Research into the behaviour of humans in emergency situations is extremely difficult as the only first hand observers are the victims 
themselves. It is not acceptable to expose people to situations which might result in their injury. It is possible to gain information by studies of naturally occurring emergencies, such as those noted in the references $(1,2)$. The effectiveness of measures designed to modify behaviour in those situations can only be inferred.

Serving a marketplace dominated by the minimum cost system for emergency only use, AFD manufacturing companies see little incentive to develop displays for fire intelligence. However, in 1981, with the benefit of the latest research into human behaviour available at that time (1), FRS specified its prototype equipment with liquid crystal 16 character text displays, to be distributed throughout a building. The 181 and 183 prototypes had $60 \times 15 \mathrm{~mm}$ displays, illustrated in Eigure 3 .

\section{Wed 15. Jun 10:58}

\section{Fire! Canteen}

Figure 3. Prototype liquid crystal fise alarm displays

Guided by the early findings from human behavioural research these displays were programmed to show:

1. the time and date in every day use;

2. that an alarm test was being carried out when relevant; and

3. during a real fire the word 'Fire!' with two levels of detail - the general area of the fire for display everywhere, but a room number for those in the immediate area of fire origin.

These were cheap in cost and power consumption, though limited in capacity and visibility. Nevertheless, when dispersed throughout a building, they might lessen the human delays following a traditional fire alarm, which appeared to arise from the very limited information content of a ringing bell.

\section{CURRENT RESEARCH INTO ESCAPE MOTIVATION}

Lack of appropriate information in emergency situations can be identified retrospectively. The effect of changing levels of information on the progress of fire drills has been observed objectively (5) and inferences drawn on the likely effectiveness in improving behaviour in fire. A human's ability to understand fire intelligence data, which might economically be offered to building occupants by advanced AFDS, may also be established objectively.

The scope of facilities which might usefully be investigated by researchers was thought by ERS to include only relatively cheap media. Mimic diagrams have been a feature of large process control plant and some AFD systems for decades, with computer generated colour graphics well represented in the former in recent years. AFD installations have tended to be economical in design because of their 'emergency only' use. The current human behavioural research (10) has therefore been limited to facillties of voice generation and graphics which can be provided by at least one popular personal computer (Commodore Amiga). Iliustrations in black and white of typical colour plan/elevation and perspective of an office building are given in Figures 4 and 5 . 


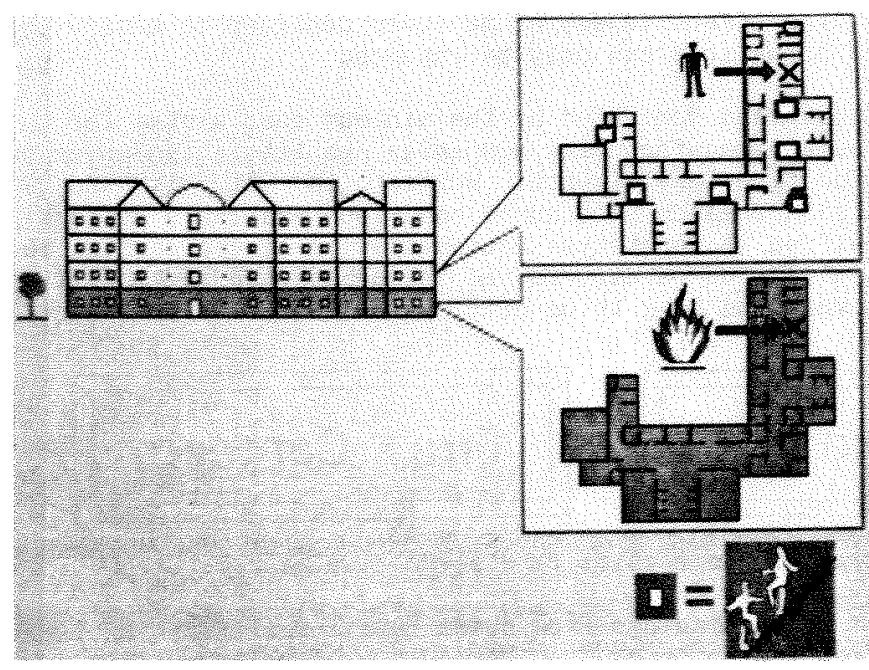

Eigure 4. Plans and elevation of an office building

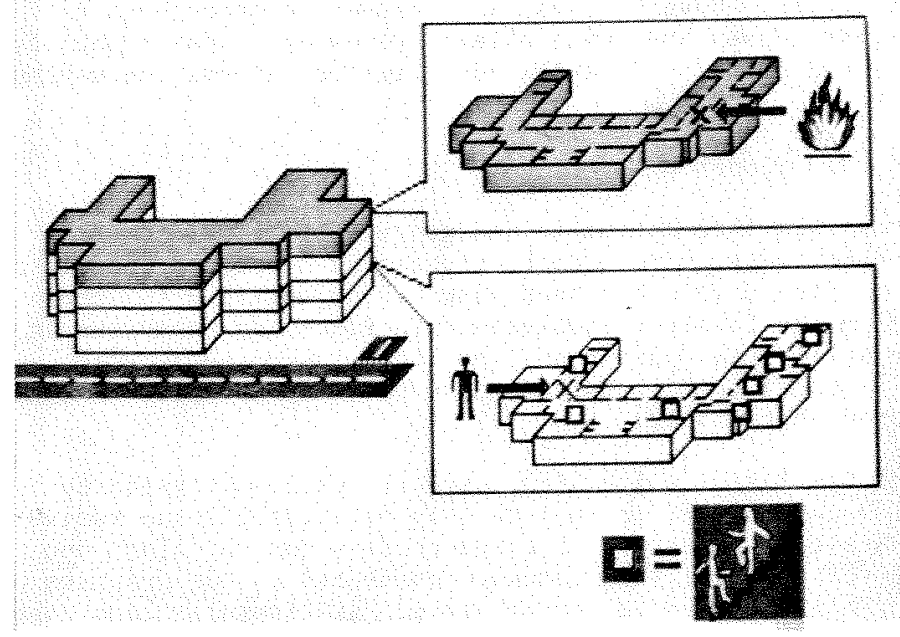

Figure 5. Perspective of an office building 
This research is designed to find the relative effectiveness (in terms of a choice to evacuate a building) of fire bells versus text versus computer generated voice versus colour graphic displays of the building (10). The research contract is not expected to be completed until the autumn of 1988. Though common sense would predict a very positive outcome, the quantification of the improvement in alarm comprehension times with the richer base of information media will be of the greatest possible interest to the fire protection community.

\section{DISCUSSION OF INFERENCES FOR EIRE PROTECTION}

For the purpose of this speculative discussion the author has assumed that current research into human behaviour will reinforce the present findings. These infer a further marked reduction in escape time from those thought to be achievable with primitive text displays which have been examined (2).

Fully effective fire protection is, by definition, such that no emergency develops. No official records exist for fires which are controlled very quickly. However, the number of ignition sources that are identified by fire brigades as causing the fires they do attend, can be very approximately calculated. Some 97 billion cigarettes are sold a year in the UK (11), which must be lit by a naked light, al though many, say half, may be smoked outdoors. In 22 million UK dwellings, let us assume at least one cooking ignition per day and perhaps $10 \%$ of that for space heating sources. The number of such ignitions is so large that it forces the conclusion that the 150,000 fires in buildings attended by the UK fire brigades every year are exceedingly rare events relative to ignitions which might give rise to major fires.

FRS sponsored studies have been set up with the promotion of safe escape as the objective. A broadcast display of a fire's location could well cause both the responsible and the curious/irresponsible building occupants to go to see it. However, the very large numbers of 'first-aid' fire fighting successes noted above also give the reassurance that if the detection of the fire is at an early stage in its growth, a building occupant adjacent to it will have a very good chance of putting it out. An analysis of fires in hospitals (12), reported by fire brigades, confirms the very high success rates ( $81 \%$ ) of first-aid fire fighting by alert building occupants.

\section{CONCLUSIONS}

The author therefore argues that the display of fire intelligence to a building population will reduce the number of fires which become major life hazards, irrespective of whether an individual chooses to leave by a safe route or fight the fire. Such a line of argument assumes the following provisos:

- the sensors must fully cover all spaces where fire might develop, such that its products reach a sensor before first aid fighting becomes dangerous;

- the spaces covered should not be so large that the occupants perceive little threat from the fire growing under a ceiling (Woolworths, Manchester; Bradford FC); 
- the fire load cannot be such that the rate of spread makes non-professional fighting hazardous or impossible (liquid fuels, high rack storage etc).

Erom the arguments advanced, the author would expect to see an increasing popularity and market share for intelligent fire alarm systems, as confidence grows in their lower false alarm rate and ease of maintenance. Clearly their cost effectiveness will increase from manufacturing scale and the falling cost of comptuting equipment.

In the longer term, the use of distributed fire intelligence could lead to a much earlier, and therefore safer, attack on a fire by both occupants and fire brigades. For equipment with suitable serviceability safeguards, improved premium reductions from insurance companies and relaxation of escape distances might well be expected.

\section{ACKNOWLEDGEMENT}

This paper forms part of the work of the Eire Research Station, Building Research Establishment, Department of the Environment. It is contributed by courtesy of the Director, BRE and reproduced by permission of the Controlier, HMSO. (c) Crown copyright.

\section{REFERENCES}

1. Canter, D. V., Studies of human behaviour in fire: empirical results and their implications for education and design. Building Research Establishment Report 1985. Avallable from the Publication Sales Office, Garston, BRE.

2. Canter, D. V., Powell, J. and BOOKER, K., Psychological aspects of informative fire warning systems. BRE report 1987 .

3. Fry, J. F. and Eveleigh, C., The behaviour of automatic fire detection systems. Fire Research Station Fire Research Note No 810 , Borehamwood, 1970.

4. Home Office, Scottish Home and Health Department. Euture Fire Policy; A consultative document. HMSO, London, 1980.

5. Tong, D., Canter, D., The decision to evacuate: a study of the motivations which contribute to evacuation in the event of fire. Fire Safety Journal, 9 (1985) 257-265.

6. Sime, J. D., The concept of panio. In: Eires and Human Behaviour (Ed. D. V. Canter), John Wiley, 1980.

7. Burry, P. E., Current research on fire detection. Eire Surveyor 1974,3 (5) $43-51$.

8. Pigott, B. B., Computer based analogue fire detection systems. Fire Engrs J., 1983, 43 (128) 23-26.

9. Pigott, B. B., The Scope for Intelligent Fire Detection Systems. pp 19-39 Proceedings of the International Fire Safety and Security Exhibition and Conference in London, April, 1986. 
10. Bellamy, L. J., Geyer, T. A., Max-lino, R., Harrison, P I., Bahrami, Z., Modha, B., An evaluation of the effectiveness of the components of informative fire warning systems. To be published: International conference on Safety in the built environment. BUSI-88. Portsmouth, England, July 1988.

11. Estimated public consumption of tobacco goods in the United Kingdom 1986, Tobacco Trades Marketing Directory, 1987.

12. Chandler, S. E., Some trends in hospital fire statistics. Building Regearch Establishment Current Paper CP 67/78. Borehamwood, 1978. 
